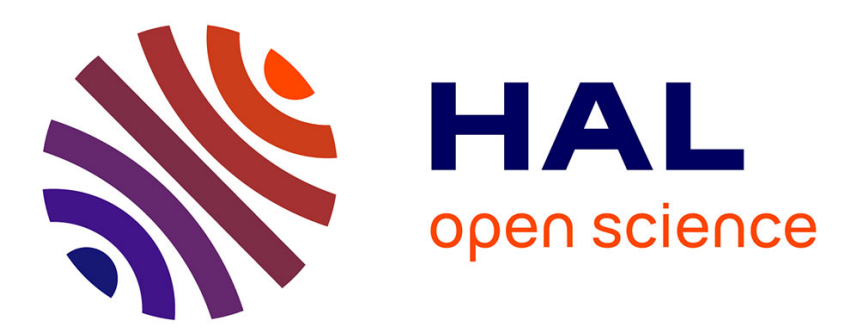

\title{
Digital bricolage: Resources and coordination in the production of digital visual effects
}

Charles-Clemens Rüling, Raffi Duymedjian

\section{To cite this version:}

Charles-Clemens Rüling, Raffi Duymedjian. Digital bricolage: Resources and coordination in the production of digital visual effects. Technological Forecasting and Social Change, 2014, 83, pp.98-110. 10.1016/j.techfore.2013.05.003 . hal-00969226

\section{HAL Id: hal-00969226 \\ http://hal.grenoble-em.com/hal-00969226}

Submitted on 2 Apr 2014

HAL is a multi-disciplinary open access archive for the deposit and dissemination of scientific research documents, whether they are published or not. The documents may come from teaching and research institutions in France or abroad, or from public or private research centers.
L'archive ouverte pluridisciplinaire HAL, est destinée au dépôt et à la diffusion de documents scientifiques de niveau recherche, publiés ou non, émanant des établissements d'enseignement et de recherche français ou étrangers, des laboratoires publics ou privés. 


\title{
Digital bricolage: Resources and coordination in the production of digital visual effects
}

\author{
Charles-Clemens Rüling \\ Charles-Clemens.RULING@grenoble-em.com \\ Grenoble Ecole de Management \\ Raffi Duymedjian \\ Raffi.DUYMEDJIAN@grenoble-em.com \\ Grenoble Ecole de Management
}

\begin{abstract}
The advent of digital technologies has led to profound changes in the creative industries, including the digitization of resources and the consequential fragmentation and greater physical distance of work practices. Looking at the production of digital visual effects for film production, this paper asks how collective digital bricolage is enabled by specific resources and involves particular coordination mechanisms. Based on a large set of interviews with industry experts, we identify the important role of two dominant coordination principles: "narrative alignment", i.e. a scene's contribution to an overall storyline, and "verisimilitude", which we define as a sense of perceptual realism. Together, these two principles facilitate collective bricolage in an increasingly fragmented and specialized professional field. Conceptually, we develop the notion of 'digital bricolage', which relies on digital assets and tools, and emphasize the need to study the impact of digitization on the nature of resources and on the coordination mechanisms emerging in specific creative industries.
\end{abstract}

\section{KEY WORDS}

Bricolage; creative industries; digital technologies; visual effects; verisimilitude 


\section{INTRODUCTION}

This paper studies the specificities of resources and coordination mechanisms enabling digital bricolage in the production of digital visual effects (DVFx). Over the last two decades, digital technologies have revolutionized the distribution and consumption of creative work. They have enabled new business models and new ways of interacting with audiences, for instance through crowdfunding and crowdsourcing (e.g., [1], [2]), they have altered the geographic organization of creative work (e.g., [3]), and they have fostered the development of new, community-based forms of coordinating work in the creative industries (e.g., [4]; [5]). But, at the same time, the advent of digital technologies has raised multiple, as yet unsolved issues about technological standards, intellectual property rights and user privacy (e.g. [6]; [7]), while digital tools and resources have not only impacted industry structures and business models, but also profoundly transformed how digital creative work is organized and carried out [8]. Surprisingly little is known, however, about the consequences of digital technologies on the production of creative work, about how digitization transforms the ways in which creative work is organized and carried out, or about how the specific nature of digital resources affects coordination among artists, engineers, managers, etc.. While some studies have addressed the influence of digital technologies on innovation, collaboration and control (see [3] for an overview), our knowledge about the impact of digitization on both the nature of the resources and coordination mechanisms used in the production of digital artifacts is still very limited. Most existing studies on the music industry, for example, have focused on changes and challenges in music distribution (e.g., [9]), but research on changing music production practices is rare (for an exception, see [10]). In other areas of creative work, Boland et al.'s [11] landmark study on how digital design and modeling tools change architectural design practices is a unusual example of research looking at the impact of digitization on creative practices themselves. 
We build on earlier work that has used the bricolage lens to study creativity and innovation ([12], [13], [14]), and on work that has highlighted the important role of bricolage in the creative industries (e.g., [15], [16], [17]), to develop the concept of 'digital bricolage' and to identify its characteristics and consequences. While bricolage has been widely used as a concept to study a range of organizational practices, the construct of digital bricolage has not yet been specifically defined or systematically investigated. As we argue in more detail below, bricolage is traditionally associated with physical closeness of actors and resources, but the digitization and dematerialization of resources has facilitated increased job specialization, and enabled greater geographical distance between the actors involved in the same creative process. So digital bricolage needs to rely on coordination mechanisms that are different from those that enable bricolage in situations in which actors and resources are colocated. Our research aims to analyze the specificities of digital resources, as well as the coordination mechanisms which enable digital bricolage in a particular empirical setting - the production of digital visual effects (DVFx). These effects play an increasingly important role in film production, and although the growing digitization of elements of film production has been tentatively addressed by film and media scholars (e.g., [18]), and management and organization scholars have studied the classic project and network aspects of filmmaking extensively (e.g., [19], [20]), the role of digital technologies in filmmaking has been understudied in organizational research.

Empirically, our study builds on an analysis of 187 interviews with digital effects professionals, conducted between January 2010 and October 2012, concerning 104 films which relied heavily on computer-generated imagery (CGI). We retrieved these interviews from a publicly accessible database of interviews in which experts discuss their work practices and the organizational processes involved in DVFx production. Based on our analysis of this data, our study makes the following contributions. In line with our earlier 
work [13], we define 'digital bricolage' as a specific form of bricolage involving digital assets and tools and intended for the creation of digital film assemblages. We show, first, that digital bricolage in a specific setting is characterized by the particular nature of the digital resources employed, and build on Bechky \& Okhuysen's distinction of material, social and cognitive resources [12] to argue that the concrete digital resources used in DVFx production have specific characteristics spanning these categories. Second, following Bailey et al. [8], we demonstrate that the coordination challenges stemming from the increasing specialization of DVFx production roles are addressed by various forms of mutual adjustment mechanisms that are enabled by flexible boundary objects and by the convergence of professionals from various specialist disciplines around the principles of the narrative alignment and verisimilitude of a given effect.

In the following sections we first discuss extant theorizing on bricolage and the specific characteristics of digital bricolage. We next present our empirical research and findings on the resources and coordination mechanisms used in the creation of DVFx, and then discuss the implications of our findings for digital bricolage in the creative industries more generally.

\section{DIGITAL BRICOLAGE}

Building on Lévi-Strauss's seminal work The Savage Mind [21], bricolage has been generally described as a process of "making do by applying combinations of the resources at hand to new problems and opportunities" ([22], p. 331). Central in bricolage studies is an emphasis on the situations in which bricolage occurs, on the process of bricolage, and on the specific resources on which bricoleurs draw ([22], [12], [13]). Extant research has studied bricolage, for example, in situations of entrepreneurial activity under resource constraint [22], such as distributed entrepreneurship in the Danish wind turbine industry [14], or as a condition for 
organizational resilience [23], such as in the ability of film crews and SWAT teams to handle unexpected events [12]. The bricolage process is characterized by three core constituents: the constitution over time of a stock of resources; a specific way of using these resources; and a specific kind of outcome [13]. Bricolage is further characterized by being associated with a specific constellation of worldviews and thought processes [24], which are strongly interrelated and form coherent and relatively stable patterns over time (e.g., [13], [25]) (see Table 1).

\section{Insert Table 1}

At the practice level, a bricoleur uses resources which have been collected during unplanned encounters, which build over time to constitute a stock of resources which they can employ in future actions. In problem solving situations, bricoleurs enter into a "dialogue" with the resources in their stock, and begin assembling them into an emergent and unpredictable arrangement which, while it is aimed at solving the problem, is not based on an ideal, preconceived solution. Bricolage proceeds through processes of permutation and substitution, trial and experimentation using resources from the bricoleur's stock, and bricoleurs will be satisfied with the outcome of this process only when (and as soon as) their arrangement "works" - in other words, when, and as long as it enables them to solve the problem they face. Bricolage relies on a coherent understanding of the world as a complex, interconnected system, in which everything matters and deserves respect and attention [13]. In a problem solving situation, this means that the bricoleur's universe is closed, and they will act primarily on what they have and know, without moving beyond the boundaries of those stocks of resources and knowledge. For Lévi-Strauss, this characteristic distinguishes bricolage from the practice of making rational choices of adequate resources that defines ideal-typical engineering work [21]. The specific worldview of the bricoleur - and the 
specific problem-solving practices of bricolage - typically rely on their familiarity with the resources "at hand," i.e. an intimate personal understanding the elements in their stock, and how they might be can be related to one another. The type of knowledge mobilized in processes of bricolage is broad and versatile, and gives actors a strong sense of self-efficacy and a high degree of resilience. In line with these ideas, Bechky and Okhuysen have shown that bricolage relies on material, social and cognitive resources: material resources include "troves of supplies and the tools needed to make use of them" ([12]: 140), for instance the use of available wood and lorry spare parts to improve wind turbines [14]; social and cognitive resources relate to organizational memory [26] - for example, enabling organizations to respond to crisis situations [23]. Material and socio-cognitive resources are closely intertwined: shared socio-cognitive resources can enable collective bricolage processes which redeploy material resources [12].

Digitization, which enables spatial separation between people and objects, and between different groups of people involved in the same project [8] may seem at odds with the emphasis on intimate knowledge, spatial proximity and shared resources in the extant literature on bricolage. But digital resources also have advantages for bricolage, in that they are easier to handle, and take up less physical space (e.g., as files stored on a disk drive - or even in 'the cloud' - rather than as images or articles on paper). Digital resources also open up almost limitless possibilities for being shared, assembled and re-combined (for instance audio files in a music mix), which has even led some authors to identify bricolage as one of the fundamental characteristics of digital culture [16]. Internet technologies also allow digital stocks to travel easily, and the digitization of creative work has in fact allowed for increasing physical distance between teams working on shared projects, for a high degree of specialization, and for tight control of resource flows across distributed teams. Increasing specialization and resource flows involving multiple locations, however, also increases such 
teams' needs for interdependence and coordination. In the digital visual effects context, for instance, multiple teams can each contribute different elements to assembling the same scene - for example, texturing, lighting, or animating specific characters - but these multiple individual inputs must be successfully integrated to accord with the film's visual and narrative continuity. As Bailey et al. [27] point out, the specialization and distance work typically associated with digitization can lead to 'gaps', which need to be bridged if the cooperation is to be effective.

To better understand how the challenges involved in digital bricolage are addressed in the context of creative work, we ask the following two research questions: What is the specific nature of the resources employed in digital bricolage? and What mechanisms are employed to enable the coordination of collective work in the context of digital bricolage?

\section{METHODS}

To study the nature of the resources and the coordination of work involved in digital bricolage, we analyzed the production of DVFx across a large number of films. We relied on a large database of interviews with DVFx specialists and effects supervisors to analyze digital bricolage in terms of the specific concrete ways in which resources were used in producing effects. Our research assumes that actors were able to talk accurately about the how they combined such resources, and that a systematic analysis of the interview texts would allow us to identify the processes of assemblage, re-use, adjustment and experimentation with digital resources, as well as the specific coordination mechanisms characteristic of this form of digital bricolage. The following sections first briefly introduce our specific research setting and then describe our research process.

\subsection{Research setting: The production of DVFx}


The possibilities offered by digitization have revolutionized film production over the past two decades [18], and visual effects which are created digitally during production and postproduction stages [28] have been at the forefront of the use of digital technologies in filmmaking. DVFx production is an act of constrained creativity - on the one hand, it is highly creative, in that effects professionals need to find innovative solutions to the challenges in front of them; but on the other, those challenges are constrained, in that they are posed by - and so must strictly align with - the script and/or the film director's vision of the scene. And, to make the task more complex, they often - particularly in the context of digitally-generated effects - involve highly fragmented processes, which may include complex and interdependent interactions among highly specialized experts (e.g. film director, effects supervisors, riggers, modelers, animators, compositors, etc.). Recent developments in digital technologies - including computer graphics and computer animation, which offer the possibilities of simulating effects or scenes in 'virtual' spaces - have had a considerable impact on the evolution of visual effects making generally, but have also added further organizational complexity into the process [29]. While, initially, digital effects were mostly used in situations when physical effects were too expensive, or the heterogeneity of the physical objects involved meant their integration could not be achieved, today's technical possibilities have extended the use of DVFx to an increasing range of filmmaking contexts. Industry sources report that visual effects can represent a significant proportion of overall film budgets, up to 40 per cent of production costs of 'effects-heavy' Hollywood blockbusters. Figure 1 represents a typical DVFx production process, and underlines its complexity and the task and technological interdependence of the many specialized professionals, firms and teams involved.

Insert Figure 1 


\subsection{Research process}

Our research developed in two stages. We first conducted an in-depth, exploratory case study [30] of one film from an early stage in the history of recent DVFx development - the highly acclaimed movie Twister (USA, 1996) - to understand the specific characteristics of digital as compared to physical effects. Based on the findings of this exploratory work, we then decided to engage in more systematic analysis of a larger database of films to focus on the nature of digital resources and the coordination mechanisms that characterize the bricolage processes involved in DVFx production. The findings presented below are based on our analysis of a large, publicly accessible database of interviews with DVFx professionals (www.artofvfx.com), from which we coded a total of 187 interviews using ATLAS.ti qualitative data analysis software. The first round of coding was inductive - one author coded the interview transcripts highlighting all the different references to the practices and coordination mechanisms involved in effects making - and yielded a set of first-order categories, such as 'motion capture', 'image enhancement', or 'seamless integration'. Moving back and forth between the data and theorizing on bricolage and digital practices, we then built more abstract second-order themes from the first-order categories. We maintained regular exchanges and discussions with two DVFx experts, based in London and Singapore, throughout the research process, who assisted us by clarifying some of the more technical issues (e.g., the role of different tools for managing project pipelines), and whose valuable comments helped us to refine our understandings of the DVFx practices.

\subsection{Data and data structure}

The data used in this study consisted of 187 interviews reported between February 2010 and October 2012 with DVFx supervisors and creative directors involved in 104 separate films which we retrieved from a publicly available, professional weblog dedicated to DVFx 
(www.artofvfx.com). The downloaded texts and images of the interviews that we analyzed comprised a total of 586 pages. Even though these interviews were publicly available, they all conveyed remarkable levels of technical and organizational detail about DVFx production, and the two DVFx experts we consulted confirmed their high quality in this regard. The set of questions established by the original interviewer was consistent across the interviews and referred to the interviewees' backgrounds and to their collaboration on specific film projects, how those collaborations were organized, what DVFx production practices were involved in creating specific scenes in the film, and the interviewees' overall evaluations of their experiences of working on those films (see Table 2 for examples of questions). Aware of the potential biases related to the use of publicly available secondary data, we took care not to focus on interviewees' positive comments about the quality of a film or of their collaboration with a specific director, but to concentrate primarily on the description of practices, resources, coordination and evaluation procedures involved in DVFx production. The fact that the interviews were conducted by a highly knowledgeable DVFx expert clearly seemed to have encouraged the specialist interviewees to talk very openly about specific technical and organizational problems they encountered, and about the specific solutions they had been able to find.

\section{Insert Table 2}

After the initial process of descriptive, 'bottom-up' interview coding we regrouped the initial codes into a set of 15 first-order categories, which were then again regrouped into five second-order themes linked to two overall dimensions - resources and coordination. In our final analysis step, we compared all interview passages related to any of the second-order themes so as to identify the common characteristics and specificities of DVFx production presented in the findings section. Figure 2 provides a schematic description of the final data 
structure: overview tables with representative quotes are presented in the findings section below.

Insert Figure 2

\section{FINDINGS}

This section presents the main findings from our analysis of the interviews about the resources specificities and coordination mechanisms used in DVFx production.

\subsection{Resources}

Digital resources comprised all the digital objects - generally referred to by interviewees as 'assets' - as well as the tools (i.e. software packages and specific algorithms) involved in producing an effect. Digital assets included data obtained from the digitizing real objects (e.g., scanning of single film images, motion capture, etc.), as well as independently programmed $2 \mathrm{D}$ or $3 \mathrm{D}$ computer graphics and effects. In this section we first outline the main digital resource-related practices revealed by our data, and then identify and categorize the characteristics of the digital resources used. Table 3 illustrates the resources and related practices involved in DVFx creation with representative quotes from the interview data.

\section{Insert Table 3}

In contrast to what we initially expected - given the virtually unlimited possibilities of computer graphics - the interviews reveal that digital assets were almost never created without reference to real objects: rather than being imagined without connection to material reality, their design in fact depended on various ways of capturing or imitating reality. Technologies for digitally capturing reality - such as film sets, objects, or actors - included photography, 3D scanning, LIDAR scanning, as well as various forms of motion capture and 
tracking used to produce 2D shots, 3D objects, complete digital sets or moving 'actors'. When producing digital assets, DVFx professionals typically drew inspiration from specific aspects of representations - such as, for instance, the surface structure of fish bones to create a "sinister looking DNA" (Martin Hill, Prometheus) or wildlife documentaries to try to perfect the behaviors and movements of computer-generated birds (Mark Breakspear, Dark Shadows). In cases where such assets were created entirely in the digital realm, their creation usually relied on some initial sketches or abstract designs, or was derived by transforming or combining digital assets from existing libraries, by reusing or adding features to assets created for earlier productions.

Digital tools constituted a particular kind of resource in DVFx production. Effects professionals typically relied on a large repertoire of highly specialized software programs to work on the various steps involved in producing their effects. Most professionals were trained to use the same standard set of tools, which generally provided a flexible framework that facilitated the development of extensions, plug-ins and proprietary solutions for specific purposes: many standard applications can be interconnected and so can exchange data - so that, for instance, the Adobe Creative Suite's layers and plug-ins can interface with its Photoshop, After Effect, and Premiere software packages. Most standard tools could also be extended with plug-ins developed in-house in order to produce the specific effects needed for a particular film. In addition, many DVFx professionals emphasized their firms' use of proprietary software tools developed in-house to address very specific tasks (e.g., particular types of explosions, flames or wet surfaces) that were not covered by standard tools and plugins. Several interviewees mentioned their importance ("I think a good effects house develops specific tools for every show" James Cooper, Cosmopolis), and some companies (e.g., MPC) emphasized their specific competencies in such software development. The open programming environment in which many such digital tools were developed and used 
enabled DVFx professionals to adapt and develop them further: we consider the existence of such an adaptable and flexible array of digital tools as one of the characteristic elements of digital bricolage.

Both existing and newly created resources can undergo various forms of treatment and manipulation during the effect production process, which highlights both the bricolage character of DVFx production and the specific characteristics of the use of digital as compared to material resources. Very frequent practices included the enhancement of various aspects of an existing shot (e.g., adding flames, changing the color of the sky), adding computer graphics (e.g., objects, clouds, debris) to an existing scene, extending specific elements of a shot (e.g., multiplying the number of lanes on a bridge, or increasing the size of an army), recreating and replacing elements (e.g., faces of actors, or surfaces of objects), painting-out and suppressing other (e.g., electrical wires, cars, or passers-by). In all their manipulations of digital resources, DVFx professionals faced the need to balance the various technological possibilities available in order to ensure that the final result would 'look right'. Interviewees for instance described their efforts in "tweaking" or "getting the best mix" to achieve a balance between various effects, technologies and constraints: these adjustments demanded a high degree of flexibility from both work practices and resources, as well as a high degree of versatility and skill from the DVFx professionals themselves. This flexibility was achieved through the adjustable tools used, the establishment of "animator friendly" systems, and a high degree of decentralized control, which allowed for continuous adaptation throughout the production process:

Since a number of shots needed to be altered as the edit progressed, and to maintain continuity, we wanted to put as much control in the hands of our compositors as possible. (Vincent Cirelli, The Avengers)

We found that the resources - the assets and tools - used in DVFx production shared several characteristics, including layering, leveling, material homogeneity, and close links 
with reality. The most important characteristic of digital assets was layering. All digital images and scenes consist of multiple layers on each of which various effects could be applied. This layering increased assets' versatility by allowing various effects and manipulations to be applied without altering the initial resource, so that any that did not yield the desired outcomes can be undone. The possibility of combining and revising work on multiple layers is a perfect illustration (in the digital realm) of Lévi-Strauss's idea of bricolage as involving permutation, trial and error, etc. until reaching the moment when an assemblage "works"[21]. Whereas, normally, most material resources can only undergo a limited number of manipulations and permutations, layered digital resources allow for specific layers to be taken away, others to be added, or layers to be re-used in different settings. Moreover, the notion of layers facilitates increasing specialization by enabling different teams to work independently on different layers of the same digital resource, and at the same time enabled the easy integration of such specialized contributions, thus increasing flexibility by providing room for experimentation and for mixing different elements.

Second, the digital nature of assets enables the dynamic definition of levels of detail, for instance for the polygonal approximation of surfaces (meshing) and the definition of textures. This makes it possible for DVFx professionals to adapt detail levels to the specific function of an asset in a given scene (e.g., foreground vs. background). Leveling enhances the versatility of assets, as the same asset can be used in multiple settings, while at the same time optimizing the computer time needed for "rendering", i.e. the generation of the final images. Third, the homogenous digital nature of all assets and software tools involved in the production process eases the seamless combination and integration of assets at and across multiple layers. Thus similar tools can be used on multiple layers, simplifying their adjustment, assembly and disassembly, and facilitating the progress of the digital design process through cycles of permutations, trial and error - again characteristic of bricolage [13]. 
These processes are only limited by the computing time required, and by the project's overall time deadlines and budget constraints (see below). However, while the technical and creative possibilities are virtually unlimited, most digital assets retain a very close relationship to reality. As we argue in more detail below, the perceptual realism of digital assets serves as an important regulative principle guiding both individuals' practices in making effects and the horizontal coordination across different teams.

\subsection{Coordination mechanisms}

To study the specific coordination mechanisms used in DVFx production, we first identified the principal dimensions and coordination in our data. Our findings show that formal coordination mechanisms defining the overall context and boundaries of a project ran alongside various forms of coordination which involve ongoing mutual adjustment, both vertically via hierarchical lines and horizontally across multiple teams. Table 4 provides an overview over the main categories together with representative interview quotes. In analyzing the data, we identified both formal and informal coordination mechanisms, as well as overarching principles. Formal mechanisms defined the overall project frame and included time and budget constraints and pipeline considerations, while the informal mutual adjustment mechanisms built on dialogue between the creative artists involved and the use of multiple boundary objects. And, at the same time, the projects were subject to two overarching coordination principles - narrative alignment and verisimilitude.

Insert Table 4

The DVFx production coordination mechanisms we analyzed from the interviews addressed the dual issues of task interdependence - related to work specialization and multiple teams working in parallel of different aspects of an effect - and technology 
interdependence, i.e. "technologies' interaction with and dependence on one another in the course of carrying out work" ([27]: 714), related to the multiple software tools and platforms whose processes and outcomes needed to be integrated, as the following interview quotes illustrate:

Our developers worked with Sitni Sati to create a Maya version of the FumeFX solver. We were able to create a volume inside of Maya, rendered through Arnold, then comped in Nuke. (Vincent Cirelli, VFX Supervisor, Prometheus)

The large storm around the Quinjet as Thor arrives to take Loki away was done using our inhouse cloud system. The tool is written into Maya and Renderman as a plug-in. The artist is able to see the volumetric clouds as he builds them in Maya, then the plug-in can take that data and render it in Renderman using its own shaders for the volume rendering. (Guy Williams, VFX Supervisor, The Avengers)

First we noted that these two coordination problems were addressed in two dimensions: vertically, involving teams, VFX supervisors and movie directors in order to define projects and tasks, and to monitor and validate progress; and horizontally, across multiple teams working on different aspects of the same scene, and so needing to ensure coherence across their various products. Second, we found two different coordination mechanisms at work in both dimensions: formal mechanisms to establish the general frame and context of a project, and various mutual adjustment mechanisms to facilitate the exchange and development of ideas and concrete proposals to address movie directors' creative ideas. Finally, we identified that all these mutual adjustment processes were controlled by two overarching coordination principles - narrative alignment and verisimilitude. We consider these various coordination mechanisms in more details below.

Formal coordination mechanisms included definitions of time and budget, as well as the 'pipeline'. First, the interviews contained multiple references to time and budget objectives, indicators and constraints. Given the general complexity of contracting for creative products [31], fixing time and budget constraints provided one way of defining project boundaries. However, interviewees referred to time and budget constraints not so much as objective boundaries, but rather as challenges for the creative teams involved, as 
defining the overall frame of resources in which they could carry out their work and pushing them to find novel solutions. In this sense, while experimenting, DVFx professionals also constantly reconsidered their ideas, for example in the light of the time needed for calculation and rendering: one of our industry experts reported that even a short scene might require several days of computing time.

Overall project coordination, monitoring and workflow was managed via the 'pipeline'. In the visual effects field, this term designates the formal production management system which serves three purposes: to handle and to track all digital resources including assets and layers; to manage the production process itself, defining who works on which version of which scene at which point in time; and to manage the final approval of scenes and layers. Various software packages (e.g., Houdini) support the management of a project's pipeline across multiple firms, enabling the progress of different production steps to be monitored, and at the same time providing the flexibility needed to integrate changes at virtually any moment in the production process. The interviewees' references to the pipeline and the associated tools pointed to a generally recognized 'tension' in creative digital work. On the one hand, digitization affords versatility via the layering of assets, a high degree of specialization, and the real-time integration of multiple experts' creative work across large geographic distances - on the other the enormous volumes of data, versions, layers, etc. generated during digital work requires new tools for coordinating those efforts and outputs. Our interviews revealed that the setting up and managing a robust yet flexible collaborative pipeline was a key requirement of a successful DVFx project.

Against the background of the high degree of division of labor, specialization, and technical coordination involved in DVFx production noted above, we also registered the very important role played by informal interactions and exchanges between DVFx professional teams and the movie's director and effects supervisor, as well as by the mutual adjustment 
mechanisms operating between effects firms, teams and individual creative artists. As we show above, formal coordination mechanisms are needed to define the boundaries of specific projects, to monitor their progress, and to handle the very large number of digital assets involved reliably. However, the central aspects of the creative work itself - such as, for example, the design and movement of characters - could only be developed on the basis of constant interaction and mutual adjustment between DVFx specialists and the movie director (or the VFX supervisor) on the one hand, and between the different visual effects firms and teams working on the same film on the other. In most cases, the overall situation was characterized by a great degree of flexibility and dynamic adaptation in creative practice, so that outcomes were not precisely defined, and creative workers were not expected to adhere unequivocally to original descriptions as they might, for instance, to animation storyboards. In the scenes discussed in the interviews, the final outcome was generally the result of ongoing dialogue between the director, the VFX supervisor, and the various teams and individuals involved.

Vertical and horizontal dialogue were mediated by boundary objects - the movie script, the storyboard, reference illustrations, photographs and videos from live shoots, demo concepts, etc. - which enabled coordination across communities by allowing for the construction of shared understandings but at the same time legitimized local interpretations ([32], [33]). In the context of our data, these artifacts could take on multiple meanings depending on the specializations of the different creative actors involved, while, at the same time, sharing the overall 'look and feel' of the scene or of the effect to be produced. Some boundary objects (e.g., the movie script) were used mainly by directors and effects supervisors to give an overall orientation to the creative process and to manage basic task interdependence, for example by attributing different scenes to different teams and estimating the time and resources required on the basis of the storyboard. Most of the boundary objects 
produced by the DVFx teams themselves took advantage of the flexibility afforded by the digital nature of assets and tools - more dynamic in nature, they provided evolving reference points for the teams' interactions with the director and the VFX supervisor and for coordinating with other DVFx production teams. Flexible boundary objects such as 3D simulations of characters or objects were continuously exchanged, presented, discussed, and subsequently modified by their proponents. The dynamic adaptability of these digitally created objects, serving as coordination devices across teams, proved particularly important in the process of convergence towards a shared understanding of the creative work to be accomplished, as this interview quote reveals:

Tim (director) wanted to have as much control over the cracks as possible, including the way the cracks moved and the size and direction of cracking. For this amount of articulation, Sam Berry, our lead rigger came up with a very complex and flexible rig. (Arundi Asregadoo, Dark Shadows)

Overall project advancement, coordination and the various forms of balancing practices described above were enabled by two different over-arching coordination principles that we could identify in the data, and which we labeled 'narrative alignment' and 'verisimilitude'. Narrative alignment was mainly referred to in vertical coordination between DVFx teams, supervisors and movie directors, whereas verisimilitude appeared as the key principle coordinating the horizontal exchanges across teams.

We defined narrative alignment as the capacity of a specific scene or effect to contribute to the movie's overall storyline, adhering to the notion of the "visual effects working for the story and character development and not the other way around" (Jeff White, The Avengers). In the interviews, instances of dialogue between effects specialists and movie directors relying on this narrative alignment principle focused, for instance, on how to translate the scene's narrative thrust into corresponding (and supporting) visual effects. This relationship between effects and narrative was not always uni-directional - in many cases, DVFx specialists' suggestions contributed to the evolution of the narrative: 
The director really liked our sequence and some of the things we were doing with the Thug, to the point that we often got notes like, "wow, that's great... let's add it to all the other shots!" or "I like it, can we double or triple the length of the shot so I can see more?" It's a lot of fun and very rewarding when the director is happy with what he is seeing and asking for more. (Chris Harvey, Battleship)

The director had every confidence in us doing a good job, so the experience was very collaborative. When he had storytelling needs that were difficult or impossible to shoot we would discuss whether there was a way to achieve it in VFfx and then go ahead with what we agreed was the best approach. (Dadi Einarsson, Contraband)

Whereas narrative alignment mainly played a role in vertical coordination, horizontal coordination was primarily governed by the principle of verisimilitude, which we can define as the perceptual realism of an effect or a scene. Over and over again interviewees highlighted the importance of realism in the effects they produced, and the role of verisimilitude as a goal to achieve and a criterion for evaluating the quality of DVFx work:

The models were ... constructed in high detail to allow for secondary movement via cloth simulations of the chain mail and cloth flaps, hair simulations for the pony tails. We compared the detail of our model against live action soldiers lit with the same lighting and revised it until we couldn't tell the difference of the digital knights from the live acting ones. (Bryan Hirota, Snow White and the Huntsman)

As recent work on the narrative roles of DVFx has discussed [18], the pursuit of verisimilitude de-emphasizes the 'spectacular' properties of visual effects and highlights the ability of effects specialists to produce photorealistic images. To our surprise, the effects specialist interviewed referred only very rarely to the spectacular, exceptional visual features of effects, but mainly stressed their realism. At first, we found this emphasis on verisimilitude at odds with the virtually unrestricted technical and aesthetic possibilities of computergenerated images, but further analysis revealed the overall importance of resources related to reality during the DVFx production process, and the need for simple references and evaluation criteria to enable the coordination and integration of images and layers across multiple actors' creative outputs. We concluded, therefore, that the reference to perceptual realism constituted an important issue for coordinating collective digital bricolage across multiple groups of actors. 
To summarize, we identified two main dimensions of coordination characterizing DFVx production. Vertical coordination involved the setting and control of time and budget objectives as well as the breakdown of the final scene into assignments for different effects firms and teams. Horizontal coordination, on the other hand, concerned the adjustment across firms and teams working on the same scene(s). Formal integration in both dimensions (including workflow and resource control, and the management of approvals) was achieved through time and budget constraints as well as through the work 'pipeline'. The mutual adjustment necessary to complement formal control was regulated by two different principles: narrative alignment was used in vertical coordination as the central criterion in evaluating the suitability of an effect or a scene in the larger context of the telling of the film's story; verisimilitude, on the other hand, was the main criterion used among DVFx specialists to evaluate the quality of the effects they produced (see Figure 3).

Insert Figure 3

As we discuss below, the emergence of a set of common references - in this case related to the idea of verisimilitude - is one of the fundamental conditions of digital bricolage, especially when teams are geographically distant.

\section{DISCUSSION AND CONCLUSION}

We first discuss the findings from our analysis of digital bricolage processes in DVFx production in the light of our two research questions, and then outline some of their consequences for understanding the notion of digital bricolage, and of digitization and digital creative work more generally.

Building on the distinction between material, social and cognitive resources proposed by Bechky and Okhuysen [12], our first research question addressed the specific nature of the 
resources involved in a digital bricolage process. In this regard, we found that all the resources reported as being used in DVFx efforts shared the common properties of digital entities: they were easy to store, move and share (within some constraints - e.g., file size). They could all be decomposed and/or recombined in a digital assemblage context, and their common digital nature allowed assets of different origins to be assembled very easily. The interconnectivity and adaptability of the software tools used further facilitated the sharing of digital assets across teams, and the extensive layering offered by the software allowed for the division of labor across multiple layers and the flexible integration of creative work on those layers.

Interestingly, most digital assets referred to in the interviews retained strong ties with reality, either by being the result of digitizing 'real' objects, or recordings of scenes, images, etc., or by being subject to the overall verisimilitude criterion. These characteristics differentiated the digital assets used in DVFx production from entirely abstract digital resources, in that their very existence presupposed some sort of material reference, either as their source or in terms of their eventual purpose. On the socio-cognitive level, this relation to materiality and realism had two consequences, which favored both individual and collective bricolage. In terms of individual bricolage, the fixed association of such resources to reality gave these digital assets a "sign"-like nature - one of the conditions Lévi-Strauss highlighted as constitutive of bricolage [21]. In terms of bricolage theory, the sign-like nature of resources is important because it both enables multiple potential usages while, at the same time, limiting or 'pre-constraining' their number. In the more general context of digital creative work, we believe that this pre-constrained nature of resources plays an important role in 'anchoring' digital creative processes in reality.

At the collective bricolage level, the specific materiality of the digital resources used in DVFx production and the common desire to retain verisimilitude in the final effect served 
to orient and guide exchanges and interaction, despite the high degrees of specialization and division of labor which often characterized DVFx work. The notion of verisimilitude provided a shared language which allowed both individual creators and their directorial supervisors to discuss and evaluate a scene or some of its aspects in a common language and from a shared understanding of their aims. In this sense, it constituted a shared sociocognitive resource which facilitated sharing of material resources and, even more important, supported collective judgment and convergent understandings. Together with the notion of narrative alignment, that of verisimilitude enabled collaboration and collective bricolage because it supported the ability of the individuals involved to judge a particular scene, using a relatively simple set of overall concepts rather than from the specific technical jargon of each DVFx specialty. We suggest these two simple coordinating principles corresponded to the "trading zones" discussed by Boland et al. [11] as shared spaces of dialogue and learning across communities.

Our findings further highlight the different forms of vertical and horizontal coordination that appear to operate in DVFx production. Formal vertical coordination mechanisms included time and budget constraints, as well as the management of digital assets and workflows through the pipeline. Interviewees referred to various forms of informal vertical coordination and mutual adjustment, and also pointed to some of the characteristics which enabled the management of collective bricolage in the digital realm. As we have outlined above, the ultimate control over narrative alignment was in the hands of the movie director who defined the film's overall narrative which the DVFx were designed to serve, and which was - typically - mapped out in various documents, including the film script, the storyboard, demo reels, etc. We argue that the particular coordinating power of these narrative artifacts stems from two sources. First, most DVFx specialists were avid consumers of the films in which their effects appeared - so that the narrative alignment of the effects 
contributing to a scene with the scene (and the overall story) was something they have learned to value in their role as consumers. (Similar observations can be made, for example, in the context of video games, where game designers are often also 'hard-core' gamers, and of music production, where composers and musicians often also spend a considerable amount of time critically listening to music.) Second, as both neurobiologists and anthropologists highlight, humans are "storytelling animals" [34], and possess a natural ability to tell, appropriate and evaluate narratives. As we have highlighted above, the emphasis on narrative alignment favors bricolage, because it does not predefine exactly how an effect is supposed to support a specific story: rather it sets an objective - how best to serves the story in a certain scene - but leaves the specific way of achieving that objective up to the effects expert working in dialogue with the director.

In the same sense, the notion of verisimilitude provided a regulatory principle which acted as a horizontal coordination mechanism across different effects firms and teams, connecting the specific indexical nature of the digital assets used to the professionals' shared understanding of what it meant to 'look real'. In their study of digital creation in architecture, Boland et al. [11] suggest this form of coordination echoes the notion of mindful interaction [35], which they find operated through the star architect Frank Gehry's overarching architectural vision, which guided associated architects in exploring new materials, techniques and technologies. In our case, the combination of the specific narrative set by the director, and the principle of verisimilitude, enabled effects specialists to work and interact mindful of the consequences of their concrete work for the overall film's treatment of its story. This form of mindfulness also included the possibility of "mindful deviation" [36] when creative work transcended the initial frame and yielded new propositions. Indeed, the interviews revealed several moments when movie directors accepted new ideas and propositions from the effects specialists which they realized enhanced the sense of the overall 
story: the following quote tells how the director of Battleship accepted an animator's suggestion for one of the film's characters:

In the beginning the Thug was never intended to have a lot of facial animation [because], initially, the visor was supposed to be almost fully opaque. That changed one day, when we took one of the close-ups and decided to give more of a hint of the emotion the Thug was going through... revealing more of his eye and face. And much to the 'chagrin' of my producer (not really) Pete (the director) liked it so much that he wanted more of it, not only in that first experimental shot but in every shot...it opened up a lot of previously completed shots. But we all knew it was the right choice and that in the end it would only strengthen the character and strength of the Thugs performance. (Chris Harvey, Battleship)

DVFx interviewees felt such mindful deviation was an acceptable outcome of digital bricolage as long as it reinforced narrative alignment and respected the principle of verisimilitude:

Ridley (the director) wasn't so fussed about what those rules were as long as it looked fantastic and the bigger story points were being served. (Paul Butterworth, Prometheus)

Narrative alignment and verisimilitude mitigated the overall fragmentation of the production and location of assets and layers, so that they all remained perceptually close to representations of reality (as compared, for instance, to an abstract data matrix). The ability of most DVFx tools to produce immediate simulations of the resulting effects enabled DVFx specialists to constantly test the narrative contribution and the verisimilitude of proposed effects during their making.

In summary, the creation of DVFx involved a generative tension between a partly undetermined outcome and a set of resources that were open but pre-constrained. We suggest that three overall conditions helped collective bricolage in this context: First, DVFx specialists were knowledgeable about most digital tools used during the overall production process - while they tended to specialize on specific steps within this process (e.g., rigging or compositing), their generalist knowledge about the principal tools also enabled them to interact mindfully with others based on a deep understanding of how their different areas of work connected. The second condition for collective bricolage in the production of DVFx was the flexibility of digital assets, based on the multiple layers that could be handled 
independently from each other. The principle of layering allowed assets to be repeatedly moved backwards and forwards, inserted, modified and extracted, assembled, disassembled and reassembled, thus enabling a whole new way of creative working, where effects ideas could be experimented with almost endlessly. The same form of flexibility existed at the level of the digital tools which enabled the transformation of layered assets, whose functions could be altered by adding plug-ins or by directly intervening at the software's programming language level. Third, the key ambition of DVFx specialists was to produce an effect that 'worked'. We identified two coordination principles - narrative alignment and verisimilitude - which between them established "trading zones" that enabled individuals and groups to engage in mindful interaction and collective learning about the underlying narrative, and to develop a shared vision of what was needed to make the scene or effect at hand 'work'. These exchanges ensured that a scene produced by multiple artists retained its realism and contributed to the overall story, but, at the same time, allowed for variations in perception among creative actors which enabled the production of 'original' effects and new ideas.

How can this study contribute to our understanding of the specificities of digital bricolage in other creative domains - such as, for instance, music, news media, photography, video games, and transmedia production? First, our study of DVFx production highlights the specific nature of digital resources in this particular area of digital creative work: while the digital nature of such resources is technically and materially the same across different domains, we expect other creative industries to rely on resources with differing sociocognitive characteristics. While the DVFx resources in this study were characterized by their reference to reality and to story, the resources involved in the bricolage processes of the sampling of electronic music, for example, might be much more abstract in nature. In the same sense, the coordination mechanisms of narrative alignment and verisimilitude may be specific to the domain of DVFx for film production: further empirical work may be needed to 
establish the precise coordination mechanisms which enable digital bricolage in other creative industries. We would expect the nature of resources and coordination mechanisms in the field of video games to be relatively close to the analysis presented above, as both video games and film, rely to a large extent on perceptual realism and narrative coherence. But to understand the processes of creative digital bricolage in different industries in empirical terms, researchers need to establish the specific characteristics of the resources used, and to identify the particular coordination principles which bound the various creative "trading zones" that develop during concrete projects. A better understanding of these principles will help to develop a better general understanding of the various forms of digital bricolage that stand at the core of the digital creative industries. 


\section{REFERENCES}

[1] D.C. Brabham, Crowdsourcing as a model for problem solving: An introduction and cases, Convergence 14(1) (2008) 75-90.

[2] M.A.M. Gobble, Everyone is a venture capitalist: The new age of crowdfunding, Research-Technology Management 55(4) (2012) 4.

[3] Y. Yoo, R.J. Boland, K. Lyytinen, A. Majchrzak, Organizing for innovation in the digitized world, Organization Science 23(5) (2012) 1398-1408.

[4] G. Lanzolla, J. Anderson, The digital revolution is over. Long live the digital revolution, Business Strategy Review 21(1) (2010) 74-77.

[5] F. Romano, The digital revolution: The world at the click of a button, International Trade Forum(3) (2009) 22-25.

[6] J. Elsom, Copyright in a digital age, Creative Industries Journal 1(3) (2011) 283-289.

[7] P.S. Menell, Governance of intellectual resources and disintegration of intellectual property in the digital age, Berkeley Technology Law Journal 26(4) (2011) 1523-1559.

[8] D.E. Bailey, P.M. Leonardi, S.R. Barley, The lure of the virtual, Organization Science 23(5) (2012) 1485-1504.

[9] J.C. Bockstedt, R.J. Kauffman, F.J. Riggins, The move to artist-led on-line music distribution: A theory-based assessment and prospects for structural changes in the digital music market, International Journal of Electronic Commerce 10(3) (2006) 7-38.

[10] A. Leyshon, The software slump? Digital music, the democratization of technology, and the decline of the recording studio sector within the musical economy, Environment and Planning 41(6) (2009) 1309-1331.

[11] R.J. Boland, K. Lyytinen, Y. Yoo, Wakes of innovation in project networks: The case of digital 3-D representations in architecture, engineering, and construction, Organization Science 18(4) (2007) 631-647.

[12] B.A. Bechky, G. Okhuysen, Expecting the unexpected? How Swat officers and film crews handle surprises, Acad. Manage. J. 54(2) (2011) 239-261.

[13] R. Duymedjian, C.-C. Rüling, Towards a foundation of bricolage in organization and management theory, Organ. Stud. 31(2) (2010) 133-151.

[14] R. Garud, P. Karnøe, Bricolage versus breakthrough: Distributed and embedded agency in technology entrepreneurship, Res. Policy 32 (2003) 277-300.

[15] P. Jeffcutt, Management and the creative industries, Studies in Cultures, Organizations and Societies 6(2) (2000) 123-127.

[16] M. Deuze, Participation, remediation, bricolage: Considering principal components of a digital culture, The Information Society 22(2) (2006) 63-75.

[17] P. Atkinson, Making opera work: Bricolage and the management of dramaturgy, Music and Arts in Action 3(1) (2010) 3-19.

[18] S.T. McClean, Digital storytelling: The narrative power of visual effects in film, MIT Press, Cambridge, MA, 2008.

[19] R.J. Defillippi, M.B. Arthur, Paradox in project based enterprise: The case of film making, California Management Review 40(2) (1998) 125-139.

[20] G. Cattani, S. Ferriani, A core/periphery perspective on individual creative performance: Social networks and cinematic achievements in the Hollywood film industry, Organ. Sci. 19(6) (2008) 824-844.

[21] C. Lévi-Strauss, The savage mind, University of Chicago Press, Chicago, IL, 1966.

[22] T. Baker, R. Nelson, Creating something from nothing: Resources construction through entrepreneurial bricolage, Admin. Sci. Quart. 50 (2005) 329-366.

[23] K.E. Weick, The collapse of sensemaking in organizations: The Mann Gulch Disaster, Admin. Sci. Quart. 38(4) (1993) 628-652. 
[24] R.E. Nisbett, The geography of thought: How Asians and Westerners think differently and why, Free Press, New York, 2003.

[25] R.E. Nisbett, T. Masuda, Culture and point of view, Proceedings of the National Academy of Sciences 100(19) (2003) 11163-11170.

[26] C. Moorman, A.S. Miner, Organizational improvisation and organizational memory, Acad. Manage. Rev. 23(4) (1998) 698-723.

[27] D.E. Bailey, P.M. Leonardi, J. Chong, Minding the gaps: Understanding technology interdependence and coordination in knowledge work, Organization Science 21(3) (2010) 713-730.

[28] Groupe de recherche des arts médiatiques, Dictionnaire des arts médiatiques, UQAM, Montréal, 1996.

[29] P. Chamberlain, From screen to monitor, Engineering \& Technology 3(15) (2008) 1821.

[30] R. Duymedjian, C.-C. Rüling, Regimes of action and bricolage in movie special effects, Vienna, 2007.

[31] R.E. Caves, Creative industries: Contracts between art and commerce, Harvard University Press, Cambridge, MA, 2000.

[32] S.L. Star, J.R. Griesemer, Institutional ecology, 'translations' and boundary objects: Amateurs and professionals in Berkeley's Museum of Vertebrate Zoology, 1907-39, Soc. Stud. Sci. 19(3) (1989) 387-420.

[33] B.A. Bechky, Sharing meaning across occupational communities: The transformation of understanding on a production floor, Organ. Sci. 14(3) (2003) 312-330.

[34] J. Gottschall, The storytelling animal: How stories make us human, Houghton Mifflin Harcourt, New York, 2012.

[35] K.E. Weick, K.M. Sutcliffe, Mindfulness and the quality of organizational attention, Organ. Sci. 17(4) (2006) 514-524.

[36] R. Garud, P. Karnøe, Path creation as a process of mindful deviation, in: R. Garud, P. Karnøe (Eds.), Path dependency and creation, Lawrence Earlbaum Associates, Mahwah, NJ, 2001, pp. 1-38. 


\section{TABLES AND FIGURES}

Table1: Practices, Worldviews, and Thought Processes Constitutive of Bricolage

\section{Categories}

Practices

World view

Thought processes

\section{Characteristics of bricolage}

Ongoing collection of potential resources, constitution of a stock of resources

Dialogue with elements from the stock

Assemblage of resources through permutation and substitution

Trial and experimentation

Disassembling and reassembling

Everything is interconnected; the world is a complex and interrelated whole

Everything matters; the value of any resource depends on the situation

Time is cyclical; all things come back to their initial state

Familiarity; things are known by direct contact and usage; knowledge by acquaintance

Attention is oriented towards the relation and potential connectivity of things Knowledge is broad and versatile 
Table 2: Examples of Interview Questions

\section{Overall theme}

Background of the interviewee and of the collaboration

\section{Organization of} collaboration

DVFx production practices

Overall evaluation

\section{Examples of questions}

What is your background?

How did Double Negative get involved on this show?

How long have you worked on this film?

How many shots have you done?

What was the size of your team?

How was the collaboration with director Rupert Sanders?

What was his approach concerning visual effects?

Can you tell us more about your collaboration with Production Visual Effects Supervisor Cedric Nicolas-Troyan?

What has Double Negative done on the show?

Can you tell us more about the filming of the Dark Forest sequence?

How did you design the Dark Forest?

Can you explain to us how you extended the set?

How did you manage so many creatures?

Can you tell us more about the Bat Fairy?

At the end Ravenna summons the Dark Fairies. How did you design it?

The Dark Fairies are composed of thousands of glass pieces. Can you tell us in detail how you created those elements and managed the simulations?

What was the biggest challenge on this project and how did you achieve it?

Was there a shot or a sequence that prevented you to sleep?

What do you keep from this experience?

What is your next project? 


\section{Table 3: DVFx Resources and Resource-related Practices}

\author{
Second-order \\ themes and first- \\ order categories \\ Assets and tools \\ Capturing reality
}

Imitating reality

Developing tools

\section{Asset manipulation}

Enhancement

Adding CG

Extension

Recreating and replacing

Painting-out and suppressing

Balancing

\section{Representative quotes}

For Sab's flagship corsair, a partial set was created for the bridge/cockpit and one deck of a single ship. This was lidar scanned and photographed for reference and recreated. (Sue Rowe, John Carter)

Second unit had access to one helicopter, which was replicated. The entire environment was then photomodeled and recreated digitally for some of the virtual camera shots. (Grady Cofer, Battleship)

For the engineer, we had to create quite a sinister looking DNA for which we used fish spines/bones as a practical reference. (Martin Hill, Prometheus)

We studied seagulls in the local area, filming how they took off, flew and landed. ... even though many of the CG gulls are small in frame, you can make out all the details we put in" (Mark Breakspear, Dark Shadows)

We wrote some new tools to enhance the capabilities of existing tools and to allow us to do new things (build clouds faster, have lightning be more controlled or even make an IBL a more positional light). (Guy Williams, The Avengers)

The large storm around the Quinjet as Thor arrives to take Loki away was done using our in-house cloud system. The tool is written into Maya and Renderman as a plug-in. (Guy Williams, The Avengers)

Almost all exterior shots where digitally enhanced by combining fields of CG pinnacles created form real rocks found in Iceland with a mountain backdrop from Wadi Rum. (Charley Henley, Prometheus)

For the alpine shot, our design team created a matte painting, dimensionalized it, and enhanced it with 3D trees, CG atmosphere and particle snow. (Paul Butterworth, Prometheus)

We added in a lot of ... atmospherics to the CG to stop it looking too clean and therefore CG. Small pockets of smoke, flambeaux, birds, sea mist, vegetation and people ... to bring the castle to life and give it a sense of scale. (Angela Barson, Snow White and the Huntsman)

We also added trees and side streets, road markings from previous road works, birds, cloud shadows and various objects that seem to be common in fishing towns on the east coast ... to liven up the streets. (Mark Breakspear, Dark Shadows)

We had about a dozen practical cars on set, essentially one lane of the bridge so we had to add additional lanes and the traffic going the other direction. (Boris Schmidt, The Amazing Spider Man)

The prologue battle ... required ... modifying the terrain so that it had a scorched earth look, extending the dark army to be many times the size of the dark army photographed ... (Bryan Hirota, Snow White and the Huntsman)

We got a digital scan of the actor ... for the face recreation in 3D. For the skin, we got early shots from SPI ... Based on this first look, we create our CG model - then there was some was back and forth on details. (Boris Schmidt, The Amazing Spider Man)

The deacon was a real puppet built for the performance on set, so we started by replicating its build digitally. We quickly discovered that we needed to augment the model ... for articulation of the muscles and joints to make it feel more like a natural, physical creature. (Martin Hill, Prometheus)

There are a bunch of aerial shots of several similar ships ... taken from helicopter. These ... had different markings and a completely different container load out, so we had to change those with CG containers and paint out and replace the markings on the ship to make them all look like the same ship. (Dadi Einarsson, Contraband)

We built the city around the set by shooting nearly 2,000 tiled spheres, akin to a high resolution Google street view. ... We had to paint out all of the cars, trees, people, streetlights, and anything that needed to parallax as the camera moves and replace them with CG assets. (Jeff White, The Avengers)

We needed to create some new lighting adjustments to add internal helmet lights. It became a balancing act of art direction between animation, lighting and comp to find the right mix of performance, light and visibility... to get the best mix of ... facial feature while keeping the Thug looking mysterious behind the visor. (Chris Harvey, Battleship)

Some of the things we paid attention to when designing the holograms included the lighting. If we pushed how much it 'flickered' for example, it looked fake. Push it too far the other way and it was hard to read, or just didn't look good. (Simon Maddison, The Avengers) 
Table 4: Coordination Mechanisms

Second-order

Representative quotes

themes and first-

order categories

General project frame

Time and

budget

In this case, the biggest challenge was the budget ... the scope of this project grew considerably through editing and post production. We really don't like to say "no" so we had to find creative solutions ... within the scope of the budget and schedule. (Jay Barton, Rock of Ages)

The biggest challenge were ... the limited amount of time and the huge amount of animation required, not only on finished shots but through an extensive postvis, blocking and editing phase. It was a pretty tight schedule with editorial changes happening right up to the end. (Stuart Lashley, Mirror Mirror)

Pipeline We had to be flexible to changes right up to the last minute. We built a pipeline to allow, if need be, animation or even model changes to update after we were signed off in lighting and compositing a shot. (Charles Henley, Prometheus)

What we learnt ... from working very closely with other VFX houses and sharing assets is the importance of having a really robust and flexible pipeline. (Aleksandar Pejik, Total Recall)

Mutual adjustment

Dialogue We started off with a discussion about the sequence with Cedric (VFX supervisor).... Our initial work involved sculpting a 3D maquette of the creature. We showed this as a 3D turntable to Rupert (director) to get sign off on the design and form of the creature. Once we had reached an agreed 3D concept we then had an object that we ... rigged. (John Moffatt, Snow White and the Huntsman)

We had several assets that were required by other vendors for their sequences. For instance, we built the Helicarrier and sent it to Weta. They created ... the damage when Hawkeye blows up engine 3 and passed it back to us ... Janek (VFX supervisor) made sure all of the vendors were staying on the same page with the look of the assets. (Jeff White, The Avengers)

Boundary The production design team pulled many different references of stock market screens but also other data objects mining graphical interfaces and elements that seemed technically cool and relevant. (James Cooper, Cosmopolis)

The weather dome was an important narrative device to isolate the Navy and alien ships into a three-on-three battle ... its design began in pre-production, with production designer Neil Spisak. His illustrators created concepts of a force field perimeter. ILM's art director, Aaron McBride, painted a progression of reference frames, representing the creation of the dome. (Grady Cofer, Battleship)

Coordination principles

Narrative

alignment

Verisimilitude
At all points through this process we're thinking about how we can best convey relevant narrative purely through quite technical data visualisations and 3D imagery. It's this pride and focus on the content that we take very seriously. (David Sheldon-Hicks, Prometheus)

We really needed the right balance of story information and suspense because it was part of a very critical moment in the movie. We worked through numerous iterations of the map ... some maps were complex, some simple but all had subtle references to the basic idea of the original Battleship board game. (Paul Mitchell, Battleship)

The main challenge overall was for us to be completely invisible and for every single shot we touched to feel like it was all in camera and for the film to never slip into the VFX genre. A lot of the comments I hear are "what visual effects?" which on a show like this is the best compliment. (Dadi Einarsson, Contraband)

Pete (director) was cautious at first. Early in preproduction, on a scout of the battleship USS Missouri, he said he wanted to have a VFX meeting at the end of the day. We met dockside, with the Missouri looming beside us. He pointed at the ship and said: "That's real. I get that. I feel that. Your effects have to be just as real and powerful as that." (Grady Cofer, Battleship) 
Figure 1: Stages in a Typical DVFx Production Process

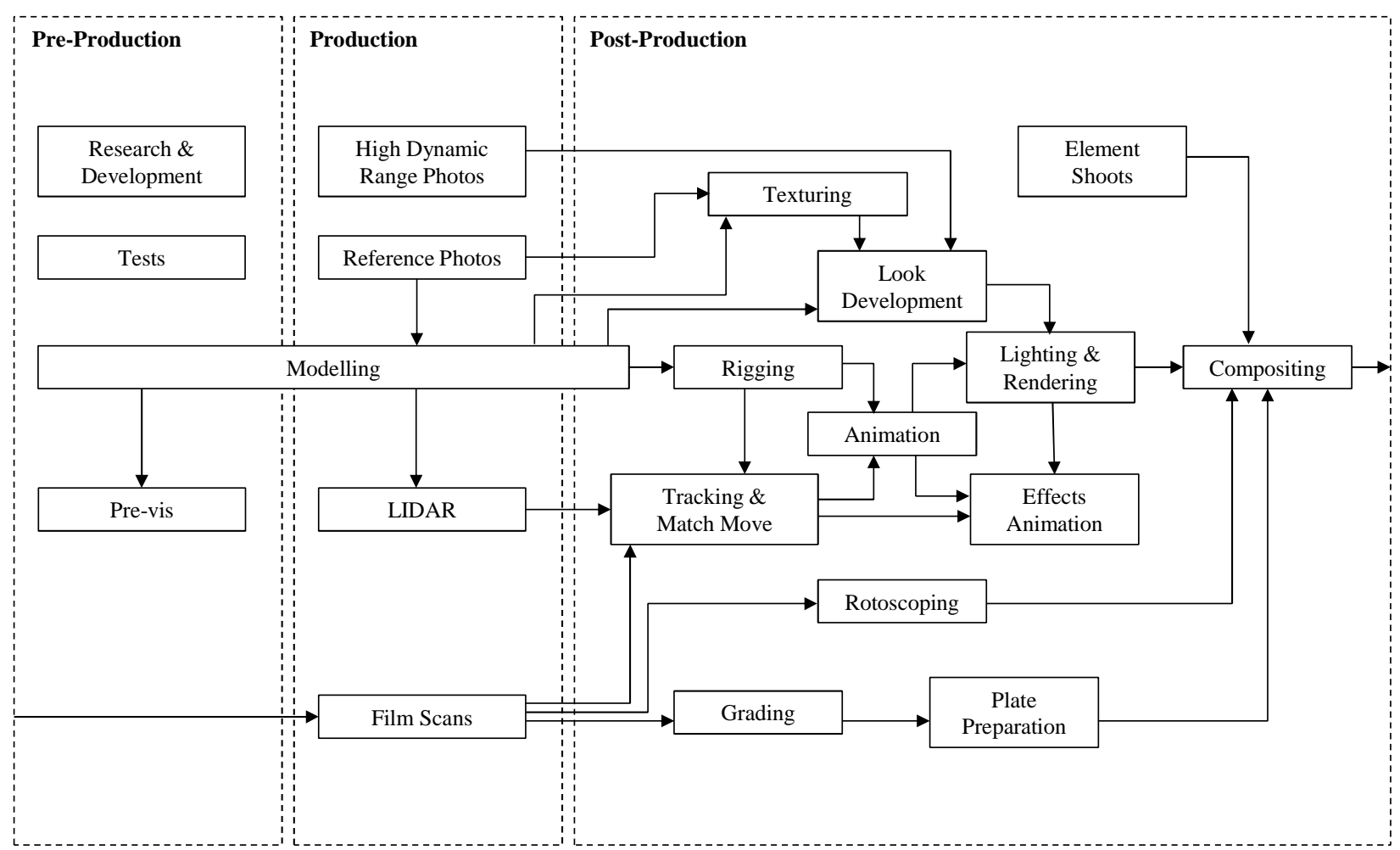

Source: Adapted from http://www.andrew-whitehurst.net/pipeline.html 
Figure 2: Data Structure
A. Capturing reality
B. Imitating reality
C. Developing tools

1. Assets and tools
D. Enhancement
E. Adding CG
F. Extension
G. Recreating and replacing
H. Painting-out and suppressing
I. Balancing

\section{J. Time and budget}

K. Pipeline

3. General project frame

L. Dialogue
M. Boundary objects

4. Mutual adjustment

N. Narrative alignment

O. Verisimilitude

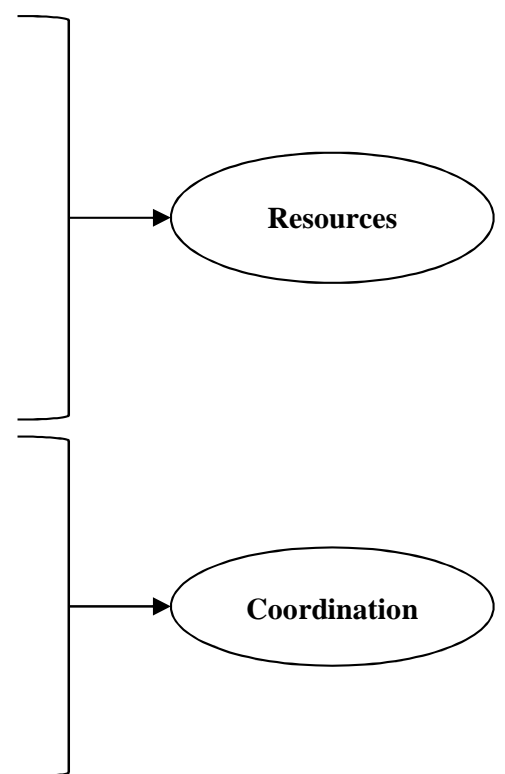


Figure 3: Vertical and Horizontal Coordination Mechanisms in DVFx Production

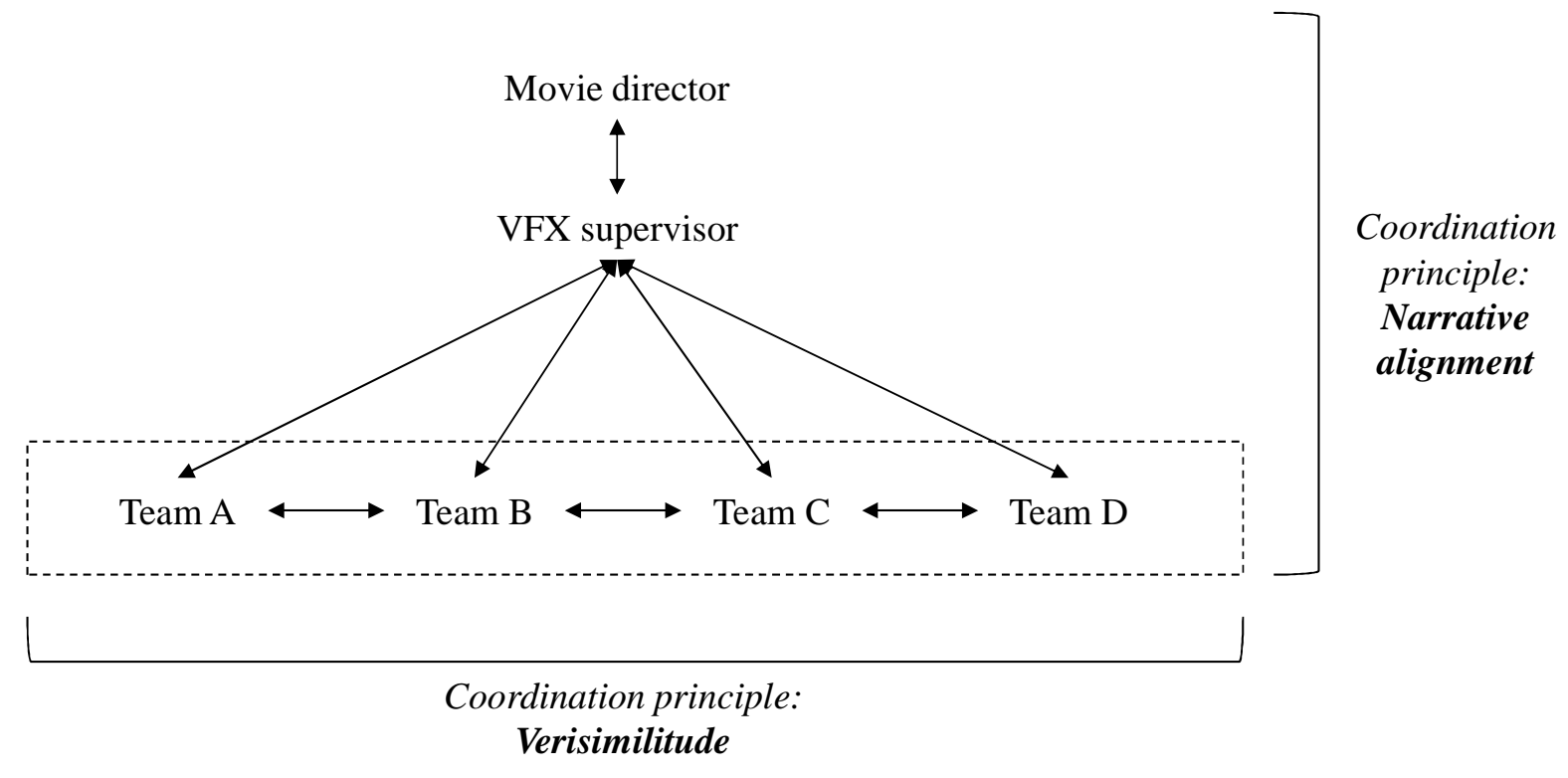

